\title{
Fatty Acid Composition of Oral Isolates of Selenomonas
}

\author{
By ERIK JANTZEN ${ }^{1}$ AND TOR HOFSTAD ${ }^{2}$ * \\ ${ }^{1}$ National Institute of Public Health, Oslo, Norway \\ 2 Department of Microbiology and Immunology, The Gade Institute, University of Bergen, \\ N-5000 Bergen, Norway
}

(Received 4 July 1984 ; revised 3 September 1984)

\begin{abstract}
Fatty acids of 16 strains of Selenomonas isolated from the human oral cavity were examined by gas-liquid chromatography. The strains showed similar patterns, characterized by the presence of straight-chain fatty acids in the range $C_{11}$ to $C_{18}$. Fatty acids of odd-numbered carbon atoms dominated and the major acids were $n$-pentadecanoate and 3 -hydroxytridecanoate. The general fatty acid pattern of Selenomonas differed distinctly from those of other previously analysed anaerobic or microaerophilic Gram-negative bacilli.
\end{abstract}

\section{INTRODUCTION}

Analysis of cellular fatty acid composition has provided valuable information for the classification of various bacteria including Fusobacterium spp. (Jantzen \& Hofstad, 1981), Leptotrichia buccalis (Hofstad \& Jantzen, 1982) and Bacteroides spp. (Miyagawa et al., 1979; Shah \& Collins, 1983). Selenomonas is a group of anaerobic crescent- to spiral-formed organisms having a tuft of flagella that arises on the concave side of the cell (Kingsley \& Hoeniger, 1973). Two species are described in Bergey's Manual of Systematic Bacteriology (Bryant, 1984): the rumen organism $S$. ruminantium and the oral organism $S$. sputigena. Recent DNA homology studies have indicated that the genus may comprise more than one oral species (Kiely \& Syed, 1984).

In this communication we report the fatty acid characteristics of 16 oral isolates of Selenomonas, and compare their fatty acid patterns with those of other anaerobic Gramnegative straight- or spiral-formed rods.

\section{METHODS}

Strains and cultivation. The Selenomonas strains ATCC 33150, IDB-2, S7-11, B 12, Ray Donut, D-3, D-8, F-1, F4, F-10, F-11, F-8N, FRY, KFS, PD-11 and Per 3 were supplied by Dr S. A. Syed, University of Michigan, Ann Arbor, Mich., USA. They were all isolated from marginal plaque of human adults or diabetic children suffering from periodontitis. Strains F-1 and F-8N were from the same patient.

Cells were cultivated on chocolate agar plates of the following composition $\left(\mathrm{g} \mathrm{l}^{-1}\right)$ : beef extract (Difco), 5.0; proteose peptone (no. 3, Difco), 10.0; NaCl, 5.0; $\mathrm{Na}_{2} \mathrm{HPO}_{4} .12 \mathrm{H}_{2} \mathrm{O}, 2 \cdot 0 ;$ agar (Difco), 13.0. The pH of the medium was adjusted to $7 \cdot 1$ with $5 \mathrm{M}-\mathrm{NaOH}$. This basal medium (1 litre) was supplemented with $85 \mathrm{ml}$ human blood and $10 \mathrm{ml}$ Isovitalex Enrichment (BBL Microbiology Systems) containing $10 \%(\mathrm{w} / \mathrm{v})$ glucose, and heated to $85^{\circ} \mathrm{C}$. The inoculated plates were incubated at $37^{\circ} \mathrm{C}$ for $72 \mathrm{~h}$ in a deoxygenated $\mathrm{CO}_{2}$ atmosphere (BBL GasPak jars). Bacterial growth was washed from the plates using a right-angled glass rod and sterile distilled water. Biomass was sedimented by centrifugation $(3000 \mathrm{~g}, 20 \mathrm{~min})$, washed twice with distilled water, freeze-dried and stored under nitrogen in closed vials at $-20^{\circ} \mathrm{C}$.

Chemicals. Solvents of analytical grade were distilled before use. The $2 \mathrm{M}-\mathrm{HCl}$ in methanol was obtained by bubbling dry $\mathrm{HCl}$ gas (Fluka, Buchs, Switzerland) into dried methanol until saturation and subsequent dilution. Fatty acid standards were obtained from Applied Science Laboratories, Oud Beijerland, The Netherlands. Trifluoroacetic anhydride was purchased from Koch-Light Laboratories, and used without further purification.

Chemical procedures and gas chromatography. Anaerobic bacteria commonly contain alk-1-enyl ethers (plasmalogens), which yield fatty aldehyde dimethylacetals upon acidic methanolysis. Primary analyses by GC and $\mathrm{GC}-\mathrm{MS}$ verified the presence of compounds with retention and fragmentation characteristics corresponding 
to dimethylacetals (Farquhar, 1962: McFadden et al., 1964) in the Selenomonas methanolysates. A procedure for removal of these constituents was therefore used (Meyer \& Meyer, 1971). Dried bacterial cells (1 to $10 \mathrm{mg}$ ) were methanolysed by $2 \mathrm{M}-\mathrm{HCl}$ in methanol $(3 \mathrm{ml})$ at $85^{\circ} \mathrm{C}$ for $18 \mathrm{~h}$ (Jantzen \& Hofstad, 1981). After cooling, the methanolysates were concentrated to about $1.5 \mathrm{ml}$ by nitrogen, $3 \mathrm{ml}$ of a $50 \%$ saturated $\mathrm{NaCl}$ solution was added and then the mixture was extracted twice with $4.5 \mathrm{ml}$ hexane. The combined hexane phases were evaporated to near dryness using dry nitrogen at room temperature. The methyl esters were saponified $(1 \mathrm{ml}$ of $0 \cdot 5 \mathrm{M} \cdot \mathrm{NaOH}$ in $90 \%$ methanol, $\left.85^{\circ} \mathrm{C}, 2 \mathrm{~h}\right)$ and the dimethylacetals extracted by hexane $(2 \times 3 \mathrm{ml})$. The remaining fatty acids (as sodium salts) were re-methylated by adjusting the $\mathrm{pH}$ to 2 with $6 \mathrm{M}-\mathrm{HCl}$, subsequent treatment with $14 \%(\mathrm{w} / \mathrm{v})$ $\mathrm{BCl}_{3}$ in methanol (Merck; $\left.0 \cdot 5 \mathrm{ml}, 100^{\circ} \mathrm{C}, 5 \mathrm{~min}\right)$ and extraction with hexane $(2 \times 3 \mathrm{ml})$.

Preparative separation of dimethylacetals and methyl esters of hydroxylated and unsubstituted fatty acids for GC-MS analysis was done on thin-layer sheets $\left(0.2 \mathrm{~mm}\right.$ silica gel, $\mathrm{F}_{254} ;$ Merck $)$ developed by toluene/diethyl ether $(10: 1)$.

Trifluoroacetyl esters of hydroxylated fatty acid methyl esters were formed by heating to boiling for 5 min with equal volumes of trifluoroacetic anhydride (Merck) and acetonitrile (Merck).

The fatty acid methyl esters were analysed using a Hewlett-Packard 5710 gas chromatograph equipped with a flame ionization detector and a fused-silica capillary column $(25 \mathrm{~m} \times 0.2 \mathrm{~mm}$, methyl silicone, OV-1) as previously described (Jantzen \& Hofstad, 1981). Peak areas and retention times were recorded by a HewlettPackard $3390 \mathrm{~A}$ recorder-integrator. Hydroxylated fatty acid methyl esters were quantified after trifluoroacetylation of the methanolysates (see above).

Peaks were primarily identified by comparison of retention times to those of methyl ester standards obtained from Applied Science Laboratories or from our collection of previously identified bacterial fatty acids. The identities of hydroxy fatty acids were confirmed by determination of their retention times before and after conversion to trifluoroacetyl derivatives. The presence of unsaturation and/or cyclopropane substitution in the alkyl chain was examined by the reduction method of Brian \& Gardner (1968).

Generally, the fatty acid identities were confirmed by MS using a Hewlett-Packard 5992 gas chromatographmass spectrometer equipped with a fused-silica capillary column $(25 \mathrm{~m} \times 0.3 \mathrm{~mm}$, coated with methylphenyl silicone, SE 54), as previously described (Jantzen \& Hofstad, 1981).

\section{RESULTS}

All strains were cultured, processed and analysed at least twice (most strains three times); the average amounts of fatty acids are given in Table 1. Unusually high quantitative variations in the fatty acid patterns of each strain were observed. In particular, the amount of $n$-tridecanoate (13:0) and $n$-pentadecenoate (15:1) fluctuated considerably from batch to batch of cells of the same strain. Accordingly the quantitative differences among the examined strains have little diagnostic value.

The 16 Selenomonas strains exhibited very similar fatty acid patterns characterized by straight-chain acids of chain length in the range $C_{11}$ to $C_{18}$. In contrast to most bacteria (Jantzen, 1984), the odd-numbered acids were generally dominant (Table 1). Most abundant in nearly all strains were $n$-pentadecanoate $(15: 0)$ and 3 -hydroxytridecanoate $(3-\mathrm{OH}-13: 0)$, whereas strains D-8, PD-11, Per 3 and S7-11 also contained considerable amounts (13:0).

Standards of 3-OH-13:U and 15:1 were not available. The identities of the two constituents given these labels were based on their gas chromatographic properties and mass spectra. Thus the presence of a hydroxyl group and its 3-position in the 3-OH-13:0 constituent was tentatively identified by the gas chromatographic retention characteristics (including shift in retention times after trifluoroacetylation) in comparison to homologues of hydroxy fatty acid standards. The mass spectrum of this compound showed the distinct fragmentation pattern of 3-hydroxy fatty acid methyl esters, including the abundant and specific $m / z 103$ fragment (Ryhage \& Stenhagen, 1960). Thus both the method of log retention time plotting and MS confirmed its identity as $3-\mathrm{OH}-13: 0$. The identity of the presumed $15: 1$ constituent was strongly supported by the characteristic shift in elution sequence (compared to $15: 0$ ), going from a nonpolar to a polar column, and its chromatographic disappearance after hydrogenation or bromination, respectively. A clear distinction from a cyclopropane substituted fatty acid was supported by the observed complete resistance towards methanolic $\mathrm{HCl}$, a reagent which degrades cyclopropane fatty acids almost completely (Vulliet et al., 1974). The identity as $15: 1$ was further supported by 


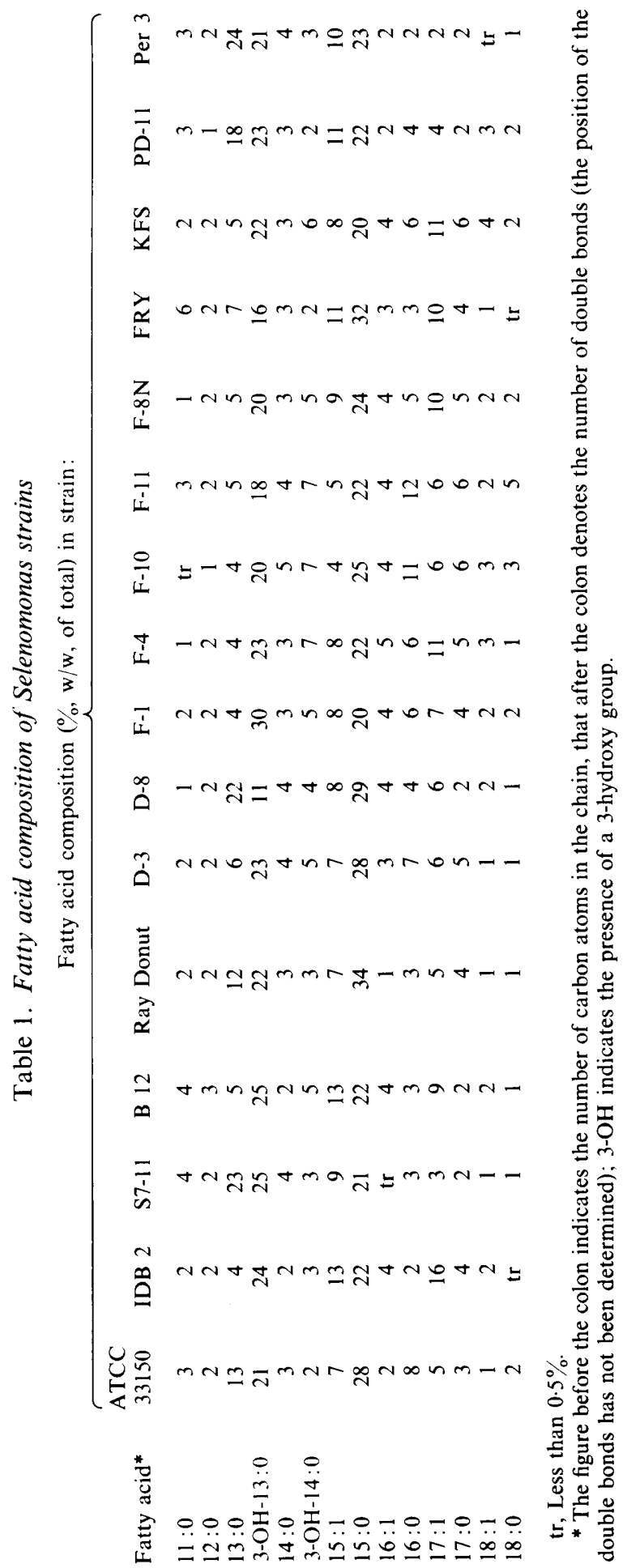


MS which provided a molecular ion of $\mathrm{m} / \mathrm{z} 254$ and the fragmentation pattern of a monounsaturated fatty acid methyl ester.

Neither cyclopropane nor methyl-branched fatty acids, could be detected. Fatty aldehyde dimethylacetals were present in the methanolysates. These constituents probably originated from plasmalogens which occur widely among anaerobic bacteria (Kamio et al., 1969; Léchevalier, 1977).

\section{DISCUSSION}

The pattern of odd-numbered fatty acids within the oral Selenomonas isolates is markedly different from other anaerobic or microaerophilic Gram-negative rods. For example, Fusobacterium species (Jantzen \& Hofstad, 1981; Calhoon et al., 1983) and Leptotrichia buccalis (Hofstad \& Jantzen, 1982) share a pattern consisting of unbranched even-numbered fatty acids in the range $\mathrm{C}_{12}$ to $\mathrm{C}_{18}$. Similarly, Campylobacter species contain unbranched even-numbered fatty acids and no odd-numbered forms (Blaser et al., 1980; Curtis, 1982). The fatty acid pattern of oral Capnocytophaga (Collins et al., 1982; Dees et al., 1982) and Bacteroides species (Miyagawa et al., 1979; Mayberry et al., 1982) differ by their characteristic methyl-branched (iso and anti-iso) hydroxylated and non-hydroxylated acids. However, a grossly similar, oddnumbered fatty acid pattern has been described for the rumen species $S$. ruminantium (Kamio et al., 1970a, 1971), which supports the placement of the rumen organism in the same genus as the human oral isolates of Selenomonas.

Unbranched odd-numbered fatty acids (i.e. $n-\mathrm{C}_{15}, n-\mathrm{C}_{17}$, and $n-\mathrm{C}_{19}$ ) are found as minor constituents in many bacteria (Jantzen, 1984). Their biosynthesis is most probably a function of the availability of the precursor propionyl-CoA (Fulco, 1983). However, for bacteria where oddnumbered acids are dominant (e.g. $S$. ruminantium), the contribution of an $\alpha$-oxidation reaction has been suggested (Kamio et al., 1970b). Emmanuel (1978), using single and double isotope labelling procedures, demonstrated that both the propionate and the $\alpha$-oxidation pathway were present in these bacteria, the latter being the most effective.

Although strains ATCC 33150, IDB-2, S7-11, B-12 and Ray Donut form a DNA homology group (S. A. Syed, personal communication) and strains PD-11, FRY and PER 3 have no DNA homology with strain ATCC 33150, these bacteria did not differ significantly in fatty acid patterns.

The results of this study indicate that fatty acid analysis may serve as a useful taxonomic aid for distinguishing Selenomonas strains from other anaerobic Gram-negative rods.

We are most grateful to Dr S. A. Syed for supplying us with the strains.

\section{REFERENCES}

Blaser, M. J., Moss, C. W. \& Weaver, R. E. (1980). Cellular fatty acid composition of Campylobacter fetus. Journal of Clinical Microbiology 11, 448-451.

Brian, B. \& Gardner, E. W. (1968). A simple procedure for detecting the presence of cyclopropane fatty acids in bacterial lipids. Applied Microbiology 16, 549-552.

BryaNT, M. P. (1984). Genus IX Selenomonas Von Prowazek 1913, 36. In Bergey's Manual of Systematic Bacteriology, vol. 1, pp. 650-653. Edited by N. R. Krieg \& J. G. Holt. Baltimore: Williams \& Wilkins.

Calhoon, D. A., Mayberry, W. R. \& Slots, J. (1983). Cellular fatty acids and soluble protein profiles of oral fusobacteria. Journal of Dental Research 62, $1181-1185$

Collins, M. D., Shah, H. N., McKee, A. S. \& KROPPENSTEDT, R. M. (1982). Chemotaxonomy of the genus Capnocytophaga (Leadbetter, Holt \& Socransky). Journal of Applied Bacteriology 52, 409415.

CURTIS, M. A. (1982). Cellular fatty acid profiles of campylobacters. In Campylobacter. Epidemiology, Pathogenesis and Biochemistry, pp. 234-24.1. Edited by D. G. Newell. Lancaster, Boston, The Hague: MTB Press.

DeEs, S. B., Karr, D. E., Hollis, D. \& Moss, C. W. (1982). Cellular fatty acids of Capnocytophaga species. Journal of Clinical Microbiology 16, 779-783.

EMmANuEL, B. (1978). The relative contribution of propionate, and long-chain even-numbered fatty acids to the production of long-chain odd-numbered fatty acids in rumen bacteria. Biochimica et biophysica acta 528, 239-246.

FARQUHAR, J. W. (1962). Identification and gas-liquid 
chromatographic behaviour of plasmalogen aldehydes and their acetal, alcohol and acetylated alcohol derivatives. Journal of Lipid Research 3, 2130.

Fulco, A. J. (1983). Fatty acid metabolism in bacteria. Progress in Lipid Research 5, 133-166.

Hofstad, T. \& JANTzEN, E. (1982). Fatty acids of Leptotrichia buccalis: taxonomic implications. Journal of General Microbiology 128, 151-153.

JANTZEN, E. (1984). Analysis of cellular components in bacterial classification and diagnosis. In Gas Chromatography/Mass Spectrometry. Applications in Microbiology, pp. 257-302. Edited by G. Odham, L. Larsson \& P.-A. Mårdh. New York, London: Plenum Press.

JANTZEN, E. \& HoFSTAD, T. (1981). Fatty acids of Fusobacterium species: taxonomic implications. Journal of General Microbiology 123, 163-171.

Kamio, Y., Kanegasaki, S. \& TaKahashi, H. (1969). Occurrence of plasmalogens in anaerobic bacteria. Journal of General and Applied Microbiology 15, 439451.

Kamio, Y., Kanegasaki, S. \& TakaHashi, H. (1970a). Fatty acid and aldehyde compositions in phospholipids of Selenomonas ruminantium with reference to growth conditions. Journal of General and Applied Microbiolog. 16, 29-37.

Kamio, Y., INagaki, H. \& Takanashi, H. (1970b). Possible occurrence of $\alpha$-oxidation in phospholipid biosynthesis in Selenomonas ruminantium. Journal of General and Applied Microbiology 16, 463-478.

Kamio, Y., KIM, K. C. \& TaKahashi, H. (1971). Chemical structure of lipid A of Selenomonas ruminantium. Journal of Biochemistry 70, 187-191.

Kiely, G. M. \& SYED, S. A. (1984). Multiple Selenomonas species in the human oral activity.
Abstract no. 143, 84th Annual Meeting of the American Society for Microbiology.

Kingsley, V. V. \& Hoeniger, J. F. M. (1973). Growth, structure and classification of Selenomonas. Bacteriological Reviews 37, 479-521.

LÉCHEVALIER, H. (1977). Lipids in bacterial taxonomya taxonomist's view. CRC Critical Review in Microbiology 5, 109-210.

MayberRy, W. R., LAmbe, D. W., JR \& Ferguson, K. P. (1982). Identification of Bacteroides species by cellular fatty acid profiles. International Journal of Systematic Bacteriology 32, 21-27.

McFadden, W. H., Wassermann, J., Corse, J., Lundin, R. E. \& Teranishi, R. (1964). Correlation and anomalies in mass spectra: acetals. Analytical Chemistry 36, 1031-1037.

MEYER, H. \& MEYER, F. (1971). Lipid metabolism in the parasitic and free living spirochetes Treponema pallidum (Reiter) and Treponema zuelzerae. Biochimica et biophysica acta 231, 93-106.

Miyagawa, E., Azuma, R. \& Suto, T. (1979). Cellular fatty acid composition in Gram-negative obligately anaerobic rods. Journal of General and Applied Microbiology 25, 41-51.

Ryhage, R. \& Stenhagen, E. (1960). Mass spectrometric studies: VI. Methyl esters of normal chain-, oxo, hydroxy-, methoxy- and epoxyacids. Arkiv för kemi 15, 545-569.

ShaH, H. N. \& Collins, M. D. (1983). Genus Bacteroides. A chemotaxonomical perspective. Journal of Applied Bacteriology 55, 403-416.

Vulliet, P., Markey, S. P. \& Tornabene, T. G. (1974). Identification of methoxyester artifacts produced by methanolic- $\mathrm{HCl}$ solvolysis of the cyclopropane fatty acids of the genus Yersinia. Biochimica et biophysica acta 348, 299-301. 